\title{
Возможна ли рабочая демократия?
}

\author{
М.Ф. ЧЕРНЫШ*
}

*Михаил Федорович Черныш - доктор социологических наук, заместитель директоpa, Институт социологии РАН. Адрес: 117218, Москва, ул. Кржижановского, д. 24/35, к. 5. E-mail: che@isras.ru

Цитирование: Черныш М.Ф. (2019) Возможна ли рабочая демократия? // Мир России. T. 28. № 2. C. 84-97. DOI: 10.17323/1811-038X-2019-28-2-84-97

В современной общественной мысли в отношении возможности рабочего самоуправления сложились два противоположных подхода - элитистский и демократический. Первый базируется на аристотелевой идее естественности производственных иерархий, извечного и непреодолимого деления общества на управляющих и управляемьх. Второй подход, нередко амбивалентный, зиждется на идее включения рядовых работников в прочесс управления. Каждый из подходов имеет длинную историю и собственных идеологов. Эксперименты по внедрению демократических подходов не смогли склонить чашу весов в чью-либо сторону. Несмотря на то, что большинство подходов оказывались неудачныли, в конечном итоге именно они подсказывали промьиленным элитам в развитых странах пути оптимизации производственной деятельности, сохранения рабочих, занятых на предприятиях, в качестве граждан, способных к разумному участию в политическом прочессе в своих странах, с одной стороны, и потребителей, готовых приобретать все более сложные продукты, производимые промышленностью, c другой. Успешность экспериментов по внедрению развитых форм рабочего самоуправления в значительной степени определялась социально-политическим контекстом, в котором они ставились, а также идеологическими установками самих экспериментаторов. Российские эксперименты по внедрению принцииов рабочего самоуправления осуществлялись в условиях предельной цеентрализации производства, господства плановой системы, сводивщей процесс принятия решений на низовом уровне к минимуму. Вместе с тем многие из форм хозяйственной самоорганизации рабочих прижились на промышленных предприятиях в развитых странах, а кооперативы, управляемые работниками, продемонстрировали высокий уровень хозяйственной эффективности. Включенность рядовых работников в прочесс управления - это необходимый шаг на пути решения важнейшей из проблем, с которыми сталкивается современное общество, проблемой неравенства. 
Ключевые слова: рабочая демократия, промышленная демократия, самоуправление, социальный эксперимент, неравенство

\section{Исходный пункт аргументации}

В общественных науках с момента их зарождения друг другу противостояли две основополагающие идеи: элитистская, которая подразумевает выделение в обществе особого слоя или группы, предназначенного к управлению, и идея прямой демократии, настаивающая на включении в процесс принятия решения широких масс населения. Аристотель в «Политике» не оставлял никаких сомнений в том, как, с его точки зрения, должно делиться общество [Аристотель 2016, с. 16]. Прялка не станет прясть сама по себе, а музыкальный инструмент не сможет извлекать чудесные звуки, если не окажется в руках достойного, того, кто способен управиться с ними. Рабство необходимо, если только человек желает сохранить за собой способность производить товары или оказывать услуги, а у каждого раба должен быть хозяин, человек управляющий, приказывающий, наставляющий. Древняя идея неискоренимости производственных иерархий в их традиционном понимании прижилась на экономической почве. В «Богатстве народов», рассуждая о силах, управляющих экономикой и обществом, Адам Смит полагал естественным такое устройство, в котором на верхних его этажах находятся собственники (и по совместительству - управляющие), а на нижних - рабочие, задача которых заключается в том, чтобы подчиняться, выполнять те предписания и распоряжения, которые готовит руководящий слой [Смит 2016, с. 61-63]. Между хозяевами и рабочими лежит не только огромная экономическая дистанция, но и статусная, а также культурная. Наблюдая однажды носильщика, который тащил его чемоданы, А. Смит задался важнейшим вопросом: в чем разница между ним, профессором экономики, и этим человеком, занятым примитивным, ручным трудом? И сам себе ответил: различия между профессором и носильщиком в том, что один имел счастье родиться в семье просвещенных родителей, сумевших дать ему образование, а второй появился на свет в семье рабочих, не знавших наук, не владевших грамотой и не способных познавать мир в абстрактных понятиях. Логика жизни такова, что дети носильщика тоже будут носильщиками, а дети профессора смогут приобщиться к наукам и, как родитель, займут достойное место в социальной иерархии. Нечего было и говорить о том, чтобы привлекать косноязычного, темного рабочего в область, где необходимы способность ясно мыслить, обширные познания и просвещенная воля. Однако и оставлять рабочего без попечения высших слоев тоже невозможно. Производство совершенствуется, распадаясь на отдельные, примитивные операции, а рабочий, которые целый день выполняет одни и те же движения, не требующие размышлений, обрекается на то, чтобы деградировать физически и умственно. Хозяева, собственники предприятий, должны обеспечить рабочим начальный уровень образования, в противном случае рабочий не сможет выполнить роль потребителя, которому вменяется в обязанность покупать на заработанные деньги продукты, которые он сам же производит.

Демократические идеи, как это ни парадоксально, опираются на те же древние источники, что и элитистская концепция. Аристотель полагал, что демократия 
таит в себе не только блага, но и угрозы цивилизованному обществу [Аристотель 2016, с. 110-112]. Благом для общества является демократия, дающая возможность включать в управление средние слои, заинтересованные в процветании государства. Пагубные последствия демократии становятся очевидны тогда, когда к власти приходит охлос - беднейшие слои населения, чьи интересы заключены лишь в том, чтобы перераспределять имеющееся богатство в свою пользу. Равенство - это важнейшее условие для свободного, неангажированного вотирования принимаемых решений, но способны ли на неангажированные суждения люди, занимающие низкие социальные позиции? В новое время идея равенства как важнейшее условие подлинной демократии получила радикальную трактовку: в руссоистской концепции подразумевались отмена всяких врожденных привилегий и построение справедливого государства, в котором волеизъявление граждан станет подлинным, а не деформированным иерархическими структурами, как это происходит в большинстве современных обществ.

Полемика о подлинности демократического волеизъявления нашла свое продолжение в лево-демократических идеях, получивших широкое распространение в XIX в. К. Маркс и его последователи полагали, что фундамент общественных отношений определяется противоречием между классами и, прежде всего, противоречием между собственниками средств производства и пролетариатом, состоящим из наемных работников. В XX в. Ральф Дарендорф писал, что в марксистской концепции противоречие между собственниками и наемными работниками - это не столько конфликт по поводу собственности, сколько напряженность, вызываемая неравным распределением власти [Dahrendorf 1959, р. 165]. Извлекать прибавочную стоимость, расширять область отчуждения собственники могут лишь потому, что в структуре производства занимают позицию господства, позволяющую им монополизировать решения по вопросам, касающимся предприятия и его рыночного позиционирования. Из этого следует, что решить проблему отчуждения можно лишь в том случае, если работники предприятия, независимо от той ступеньки, которую они занимают в иерархии предприятия, получат возможность участвовать в процессе принятия ключевых для них решений. Р. Дарендорф, как и социологи ранних формаций (например, Питирим Сорокин), был убежден в интегрированности и гомологичности социальных институтов. Демократия не может быть подлинной, если в обществе остаются даже не острова, а целые континенты, в которых процветают иерархии господства, закрепляющие привилегии отдельных классов и слоев. Можно, разумеется, в опровержение данной идеи утверждать, что рабочие - не только «винтики» производственного процесса, но и граждане, способные посредством демократических процедур смягчать отношения господства на предприятиях. Они, к примеру, могут отстаивать права профсоюзов и, прежде всего, их право контролировать состояние рабочего места, процедуры найма и увольнения работников. Однако как ни важна роль профсоюзов в странах Запада, у них, тем не менее, нет возможности определять стратегические цели развития предприятия. Эти решения, имеющие огромное влияние на судьбы рядовых работников, собственники предприятия и его управляющие оставляют за собой.

В российском контексте по мере перехода экономики к капиталистическим формам хозяйствования противоречия, связанные с трансформацией системы господства-подчинения, неизменно принимали форму острых социальных конфлик- 
тов, отсылающих скорее к производственным практикам девятнадцатого века, чем века двадцать первого. Стремясь к максимизации прибыли, российские собственники прибегали в прошлом и нередко прибегают в настоящее время к задержкам выплат заработной платы, массовым сокращениям персонала, перепрофилированию предприятий с понижением качества и технологического уровня производимой продукции ${ }^{1}$.

\section{Принципы управления: инклюзия или эксклюзия?}

В теоретической полемике о возможностях внедрения демократических процедур управления предприятиями выдвигается ряд аргументов, которые якобы опровергают саму возможность включения рабочих в процесс принятия решений. Противники рабочей демократии ссылаются на предыдущий опыт, который, как правило, был отрицательным. В частности, в статье А.Н. Медушевского «Государство-Коммуна: эксперимент рабочей демократии в России 1918 г. и причины его крушения», опубликованной в этом номере журнала [Медушевский 2019, с. 63-83], анализируется историческая канва и результаты социальных экспериментов по внедрению демократических методов принятия решений на российских предприятиях в первые послереволюционные годы. Из этого опыта с определенностью следует, что «игры в демократию», как правило, приводят к кризису управления, потери несет не только государство, но и сами рабочие, чьи действия, по сути, останавливают процесс принятия рациональных рыночных решений, а результатом становится возникновение новой иерархии, не имеющей ничего общего с первоначальной идеей. Подразумевается, что структура возрождается через сохраняющиеся паттерны господства и подчинения внутри культуры, которые в послереволюционном обществе соединяются с репрессивными практиками в отношении отдельных классов и слоев.

Подобная линия рассуждений и аргументы, к которым прибегают ее сторонники, имеет в своей основе долгую историю: элитистских взглядов придерживался, к примеру, признанный классик российской социологии Питирим Сорокин [Сорокин 2005]. Рабочие, полагал он, в ходе революции становятся объектом злостной манипуляции. Революционеры внушают им ложные идеи о возможности обойтись без хозяев, о построении государства подлинной справедливости. Однако как только революция завершается и наступает неизбежный термидор, разговоры о рабочей демократии оказываются пустословием, а вместо старой, несправедливой, но привычной системы господства и подчинения учреждается новая, во многом раз более жестокая, имеющая своей целью восстановление повиновения. Дело в том, что по-иному эта система действовать не может, поскольку само производство возможно лишь в том случае, если оно опирается на логику господства и подчинения. Место крестьян - у сохи, рабочих - у станка, а хозяев - за письменным столом, именно так устроен социальный мир. Эмигрировав в США, П. Сорокин, в прошлом социалист-революционер, начал писать статьи,

\footnotetext{
Подробный анализ того, как это происходило, можно найти в работах Саймона Кларка, внимательного наблюдателя тех процессов, которые развивались в ходе приватизации и по ее завершению [Clark 2007].
} 
оправдывающие неравенство и рисующие американских капиталистов как людей, преданных делу, отдающих себя работе, иногда в ущерб семейной жизни [Sorokin 1925]. Подобные идеи вряд ли помогли убедить население страны в том, что неравенство идет во благо общества, если учесть, что ровно через четыре года после опубликования произведенной Сорокиным похвалы капитализму разразился беспрецедентный по масштабам кризис, приведший к Великой депрессии, многочисленным людским потерям, о которых американская историография говорит полушепотом, избегая болезненных подробностей.

Логика отрицания самой возможности рабочей демократии не только у П. Сорокина, но и, к примеру, у Айн Рэнд, апофатическая [Рэнд 2018]. Айн Рэнд находит аргументы, которые призваны убедить читателей в преимуществах капитализма и безраздельного господства имущих, в результатах gedankenexperiment, мыслительного эксперимента по удалению элиты, включая управленцев и хозяев предприятий в либеральный затвор с оставлением рабочих без высшего попечения. В романе «Атлас пожал плечами» рабочие, оказавшиеся без высших классов, так и не смогли наладить управление предприятиями, что в конечном итоге привело к глубокому кризису и коллапсу в экономической и социальной жизни. Тем не менее высокопарные рассуждения Айн Рэнд не нашли серьезной поддержки у современников: Гор Видал назвал ее произведения и философию, которую она предлагала принять, безальтернативной, «почти совершенной формой аморализма» [Vidal 2008]. Эксперимент, поставленный Айн Рэнд, остался без внимания социологов, притом что на тот момент (речь идет о конце 1950-х гг.) американская социология находилась на пике своего влияния. Дело здесь не только в литературных качествах упомянутого произведения, но и в том, что полное или частичное удаление правящих элит происходило в истории неоднократно, но при этом крайне редко приводило к тем последствиям, о которых писала Айн Рэнд. Причиной трагедий, если они случались в подобных случаях, была не столько утрата элиты, сколько сопутствующие обстоятельства: войны, восстания и революции. Убедительным ответом на вызов, брошенный Айн Рэнд и другими сторонниками крайнего либертарианства, можно считать то определение элиты, которое дал в своих трудах Вильфредо Парето: элита это всего лишь верхний слой в каждой из сфер жизни [Pareto 1963]. Выведение из оборота верхнего слоя создает условия для мобильности тех, кто ожидает своего шанса на мобильность, и это регулярно происходит в процессах естественного воспроизводства элиты, когда на смену старым лидерам приходят новые, включающие в себя выходцев из низших слоев. Ускоренная смена элит, возможно, и приведет к потерям социального и культурного капиталов, но уже точно не остановит социальную и экономическую жизнь, точно не станет причиной вселенской катастрофы. «Железный закон» бюрократии относится и к той ситуации, в которой часть бюрократии по какой-то причине выводится из оборота, а освободившиеся клеточки в шахматной диспозиции власти заполняются новыми фигурами, готовыми взять на себя функции управления.

Отсылка к шахматам здесь не случайна: именно создание шахматного клуба принял за основу Ш. Айзенштадт, чтобы показать, как формируется стратификационная пирамида в организации [Eisenstadt 1974]. В некотором смысле это тоже был «мыслительный эксперимент», но с иными, чем у Айн Рэнд результатами. За исходное состояние Ш. Айзенштадт взял ситуацию, в которой несколько игроков 
в шахматы, знакомые, по-видимому, неформально, решили организовать структуру - шахматный клуб. На первом этапе игроков, которые к этой структуре присоединяются, совсем немного, поэтому и процесс управления ею несложен, но тем не менее уже на этом этапе необходимо назначить руководителя клуба и казначея. По мере того как клуб прирастает новыми членами, в нем возникают новые иерархии, например, иерархия игроков по уровню достижений: чемпионы, регулярно одерживающие победы в соревнованиях, будут иметь в этой структуре более высокие позиции, чем менее опытные игроки. А далее (в том случае, если клуб продолжит развиваться) возникнет слой «старожилов», вступивших в клуб раньше других и сохраняющих его традиции, и они займут в нем более высокую позицию, чем остальные. В какой-то момент клубу понадобится сформировать правление, которое, разумеется, будет организовано в полном соответствии с демократическими правилами. Представители, избранные рядовыми членами организации, будут принимать ключевые решения, касающиеся организации или же (в некоторых случаях), когда предметом обсуждения станут сверхважные вопросы, отдавать распоряжение о проведении плебисцита, охватывающего всех его членов. Дифференциация функций порождает стратификацию, и чем больше организация, тем более специализированными, требующими особой подготовки становятся функции управления ею. Но означает ли это, что рядовых работников вообще следует вывести за рамки принятия решений, предлагая им принимать все то, что готовит для них руководство? Очевидно, что элитистская логика находится не внутри, а вовне организации и вряд ли совместима в полной мере с теми принципами, которые в ней заложены. Дифференциация способствует становлению стратификации, но при этом в ней сохраняются функциональные принципы распределения позиций и заменяемость людей, занимающих их. Эти принципы остаются действенными лишь до того момента, пока какая-то группа не выразит желание сделать клуб своей собственностью и перераспределить финансовые потоки или символические капиталы в свою пользу. В подобной ситуации присутствие в руководстве иной воли, кроме воли новоявленных собственников, будет покушением на их интересы. Здесь обнаруживает себя существенное различие между обыкновенной организацией и организацией, имеющей частных собственников, заинтересованных в прибыли. Возникновение распределительных отношений, находящихся за рамками собственно организационной логики, становится импульсом к изменению институциональной основы внутриорганизационных отношений. Институты в подобной ситуации не имеют той нейтральной уравнительной функции, которая им зачастую приписывается. Они превращаются в инструмент защиты и усиления позиций лиц, заинтересованных в том, чтобы ad infinitum использовать организацию для собственного обогащения.

Суммируя аргументы против кооптации рядовых работников в систему управления, можно свести их к двум основным пунктам. Во-первых, рядовые работники не могут управлять предприятиями потому, что не обладают должной компетенцией. Сторонники подобной точки зрения делают в этом случае тонкую подмену понятий, отождествляя компетенцию и социальный интерес. Действительно, даже левые социологи (например, Э.О. Райт) не отрицают, что управленческая компетенция - это особый актив, которым большинство рядовых работников не владеют или владеют не в полной мере [Wright 1985]. Оставим в стороне важный вопрос о том, как приобретается данный актив, каким образом 
преодолевается граница между работниками, находящимися на исполнительских позициях, и теми, кто осуществляет руководство. Важно понимать, что это всетаки разные позиции, и управленческий интерес не всегда тождественен интересу собственника. Мем «эффективный менеджер», который, по сути, изнуряет и разрушает вверенное ему предприятие, появился в ответ на ситуацию, когда руководство слепо выполняет поручения хозяев предприятия по максимизации прибыли, ориентированных на короткую перспективу. Политика хозяев может в некоторых обстоятельствах (а в российской экономике подобные обстоятельства возникают постоянно) диктоваться своеобразным желанием получать высокие прибыли за счет чрезмерного износа основных фондов и занижения фонда оплаты труда с одной лишь целью «обналичить» институциональный ресурс, выраженный в отношениях собственности, и достичь вожделенного состояния рантье для себя и своих отпрысков. В подобной ситуации важно, чтобы интересы собственников модерировались активным участием работников в управлении предприятием и существовал противовес эгоизму собственников в формах, позволяющих влиять на принимаемые решения. Известно, что в российской экономике эгоизм собственников сдерживается государственной волей, заставляющей хозяев держать предприятия на плаву. Происходит это тогда, когда рядовые работники выходят на улицы, перекрывают магистрали, когда протест против закрытия предприятий или их перепрофилирования грозит серьезными социальными катаклизмами. Не лучше ли было бы предупреждать подобные конфликты, уравновешивая центры принятия решений? Не было бы правильнее для всех участников процесса, если бы рядовые работники, знающие ситуацию изнутри, были вовлечены в процессы принятия самых важных для компании решений?

Второй аргумент, возможно, более серьезный, чем первый, заключается в том, что рядовые работники не способны к креативной деструкции - радикальной перестройке или закрытию производств с целью внедрения новых технологий, уменьшения доли ручного труда в пользу труда квалифицированного. Противовес подобному аргументу может быть найден в практиках японских компаний, построенных на семейных принципах и демонстрирующих более высокий уровень эффективности, чем предприятия, в которых интерес рядового работника никак не учитывается. Японский опыт свидетельствует о том, что рабочие готовы принять планы модернизации в том случае, если они не грозят им потерей средств к существованию, если компания параллельно создает новые производства или иные отделения, где труд увольняемых работников может пригодиться [Dohse, Jürgens, Malsch 1984].

Ни один из высказываемых аргументов не имеет прямого отношения к малым предприятиям, которые, функционируя на рыночных принципах, могут иметь форму полной коллективной самоуправляемости. В российском опыте подобные предприятия существовали издревле и носили название «артели». В исторической перспективе артель оказалась одной из наиболее живучих форм организации производства в российской экономике [Новиков 2009]. Второй формой самоуправления, оправдавшей себя в исторической перспективе, был кооператив. Напомним, что кооперативы множились и захватывали потребительский сектор рынка во времена перестройки, оставив о себе парадоксально плохую память. Негативный имидж, который они приобрели в эпоху экономической ломки, объясняется тем, что эта гибкая и в большинстве случаев эффективная 
форма хозяйствования поселилась и открыла для себя широчайшие возможности в экономике, где до того господствовали неповоротливые, не чувствовавшие потребителей централизованные государственные структуры. В экономике, где все было в дефиците, от колбасы до приличной обуви, оказалось возможным делать целые состояния, не создавая новой потребительской стоимости, а лишь приближая ее к области спроса.

\section{Исторические уроки}

Вернемся к уже высказанному доводу о том, что в российской истории эксперименты в области рабочей (промышленной) демократии всегда или почти всегда имели отрицательный результат. Закономерный вопрос, который следует задать сторонникам подобной позиции, может быть сформулирован следующим образом: какую роль в этих практиках играл социально-экономический контекст, в котором они осуществлялись? Как уже говорилось выше, артельный труд в России был вполне эффективен. Провальными же оказались эксперименты, проводившиеся в условиях военного коммунизма и много позже в период перестройки, когда они приняли форму выборов директоров предприятий. В каждом из названных случаев контекст - идеологический, институциональный - оказывался более значимым, чем параметры самого опыта. Обстоятельства, в которых делались попытки учредить самоуправление, формировались парадигмой предельного огосударствления промышленной деятельности, полного контроля государства над любыми процессами в экономике (о чем справедливо пишет А.Н. Медушевский [Медушевский 2019]). В этой ситуации рабочее самоуправление обладало крайне слабыми институциональными основаниями и не имело шансов идти вразрез с теми целями и ограничениями, которые навязывалось государством производственных структурам. О каком самоуправлении могла идти речь в условиях, когда цели предприятия имели форму директивного плана, отклонение от которого приравнивалось к правонарушению и примерно наказывалось? Выборы директоров стали имитацией самоуправления: во главе предприятий оказались фактически те же «красные директора», успешно применявшие административные ресурс для достижения своих целей.

Если обратиться не к российской, а зарубежной истории, то опыт самоуправления, «промышленная демократия», по выражению супругов Уэбб [Webb $S$, Webb B. 2013], демонстрировал противоречивые результаты. Эксперимент Р. Оуэна в Нью-Ланарке по созданию рабочей коммуны «Новая Гармония» потерпел неудачу, но в чем была подоплека неудачи, и в чем он все-таки оправдал себя? [Harrison 1969]. Одна из причин заключалась в том, что эксперимент с самого начала принял форму коммунистической утопии: речь шла не просто о самоуправлении, а об общности жизненных условий и довольно строгой регламентации личной жизни. Успехи, которых добился Р. Оуэн, поражали воображение современников: пестрая совокупность людей разных сословий и занятий в условиях, когда во главу угла ставится общее благо, оказалась способной к принятию разумных коллективных решений. Один из создателей коммуны «Новая Гармония» Джошиа Уоррен полагал, что причинами, поставившими предел коммуни- 
стической утопии, было стремление Р. Оуэна и его единомышленников довести обобществление до последней черты, заставить работников отказаться от частной собственности во всех ее формах и насадить коллективизм там, где должна сохраняться свобода воли [Warren 2011]. Иными словами, эксперимент не оправдал себя в той части, где ставилась цель регулировать и регламентировать жизнь рабочих за рамками производственного процесса. Что касается процесса принятия производственных решений, то в этой части практика по включению работников в управление была вполне успешной. Важно и то, что при принятии решений воля коллектива соединялась с мнением квалифицированного управленца, заполнявшего лакуны в понимании технологий или рыночных условий, в которых должно было работать предприятие.

О том, что включение рабочих в процесс управления может быть эффективным инструментом сдерживания интересов собственников и повышения производительности труда, писал не кто иной, как восславленный В.И. Лениным Ф. Тейлор [Slattery 2003, pp. 175-177]. Тейлоризм и фордизм, повышая эффективность производства, подавляют мотивацию к труду, обессмысливают его. Рабочего, полагал Ф. Тейлор, необходимо сделать полноправным собственником, владеющим предприятием наряду с теми, кто держит контрольный пакет акций. Только в этом в случае у работника может возникнуть настоящая заинтересованность в эффективности своего труда и понимание того, зачем нужно работать с полной отдачей. Как показала история, лица, контролирующие предприятия - кем бы они ни были, советскими бюрократами или американскими менеджерами, - крайне неохотно идут на уступки в вопросах включения низшего слоя в процесс управления. Ведь речь идет не только о господстве как таковом, но и о процессах, приносящих прибыль, а в этом вопросе компромисс либо исключен полностью, либо сведен к усеченным формам, когда основные рычаги контроля, в том числе над процессом распределения, остаются в руках собственников.

Идея освобождения труда и перехода к труду без принуждения давно бродит в развитых обществах как призрак, принимающий иногда материальные формы в экспериментах или же специфических практиках, вполне, кстати говоря, себя оправдывающих. Советская концепция управления социалистическим обществом через профсоюзы несла на себе печать предыдущей эпохи, той логики, в которой осуществлялись революционные преобразования. Очевидно, что выдвижение этого замысла на первый план не произошло, если бы не было соответствующего вполне успешного западного опыта. В европейских странах эволюция рабочего участия происходила постепенно, шаг за шагом, одним из которых стали так называемые товарищества в Великобритании (friendly societies) и некоторых других странах. В этих сообществах в отсутствии государственной системы социальной поддержки развивались продуктивные формы сознательного взаимодействия по социальным вопросам: товарищества поддерживали своих членов, если те попадали в сложные обстоятельства, оказывали им финансовую помощь в случае болезни или затруднений материального свойства; они брали на себя организацию совместных праздников, дружеских встреч, чествований, если таковые намечались. Товарищества становились чем-то вроде клуба, в котором каждый член мог рассчитывать на формальную и неформальную поддержку всех остальных. В конце XIX в. в Великобритании почти $90 \%$ всех работников входили в одно или несколько товариществ. В советском опыте подобные формы взаимодействия тоже 
существовали, именуясь кассами взаимопомощи, но их функции были серьезно урезаны: речь шла лишь об умеренной единоразовой помощи, которые лица, входящие в кассу, могли получать в особых случаях.

Идея совместного управления частной сферой не могла не перерасти в область совместной организации и управления производством. Не только в западных, но и развивающихся странах возникла и укоренилась такая формы хозяйственной деятельности, как кооператив. Кооперативное движение стало одной из форм объединения рабочих в производственные единицы и, по мысли В.И. Ленина, должно было стать одной из основных форм хозяйствования в Стране Советов [Ленин 1970]. Кооперативное движение осталось, но только как деятельность, подчиненная централизованной власти. Во многих странах кооперативная форма хозяйствования прижилась и стала, наряду с другими типами частных предприятий, одной из обычных, принятых системой, форм организации производства. Живучесть кооперативов подтверждается многими наблюдениями, опровергая утверждения о том, что рабочие не способны успешно вести совместное хозяйство в условиях рыночной экономики.

Обращает на себя внимание ряд экспериментов по включению рядовых работников в процесс управления производством, которые проводились во второй половине XX в. в некоторых странах Европы и Азии: в частности, в Норвегии были получены весьма обнадеживающие результаты при предоставлении рабочим автономии и права принятия решений [Emery, Thorsrud 1976]. В эксперименте Христиана Спигеверка делалась попытка делегировать рабочим управление производственным процессом на низовом уровне, при этом вмешательство извне осуществлялось с одной целью: исключить по мере возможности всякое внешнее влияние на процессы, которые были объектом наблюдения. Рабочие проволочной фабрики (ответ А. Смиту из будущего) взяли на себя ответственность за решения, которые до того были прерогативной менеджмента. Как только рабочие реально включилась в процесс управления, многие из операций, которые выполнялись в тех подразделениях, в которых проводился эксперимент, были оптимизированы. Производительность труда, вопреки ожиданиям скептиков, не только не упала, но и повысилась на 20\%. Благодаря низовому самоуправлению удалось снять полностью или частично многие из тех конфликтов, которые зрели в коллективе и, в частности, противоречия по поводу оплаты труда.

Второй эксперимент, проведенный на фабрике «Гунсфос», имел более сложный дизайн: рабочим предлагалось участвовать в управлении не только в низовых подразделениях, но и на уровне предприятия в целом. И хотя не обошлось без сложностей и застоя на первых порах, в дальнейшем проблемы взаимодействия профессиональных управленцев и рабочих комитетов удалось преодолеть, были созданы и прошли апробацию стандартные формы совместного принятия решений. Опыт оказался в целом успешен, а его результаты в форме стандартных процедур взаимодействия между разными уровнями управления стали активно внедряться на других предприятиях.

Особенно впечатляющими выглядят социальные эксперименты по рабочему самоуправлению на металлургическом заводе «Нобо», где небольшой коллектив одного из цехов (30 чел.), занятый производством обогревателей, работал в обычном режиме разделения трудовых операций в полном соответствии с принципами эффективного труда, предложенными Ф. Тейлором. Заработная плата была 
сдельной и зависела от объема выпускаемой продукции. В ходе эксперимента принципы организации труда и формы его оплаты были изменены: работники получили возможность самостоятельно распределять обязанности на рабочем месте, дополнительно освоили несколько трудовых операций, стали получать фиксированную заработную плату, к которой добавлялись премиальные по результатам труда. Коллективные формы принятия решений стали обычной практикой, что позволило директору предприятия перенести акцент в своей деятельности с внутренней организации на отношения с партнерами предприятия. Этот эксперимент существенно повлиял на управление норвежскими промышленными предприятиями, его выводы брались за основу при организации труда на других фабриках и заводах. В практиках, которые теперь распространены не только в странах Скандинавии, но и в Германии, Италии, Франции, участие рабочих, объединенных в профсоюз или иными образом, в управлении предприятием считается обязательным условием его успешного функционирования.

В современной российской экономике господствует иной, элитистский, менеджериальный стиль управления, характеризующийся строжайшей регламентацией труда, минимизацией вложений в новые технологии, удержанием заработных плат на самых низких значениях. Можно лишь надеяться, что в будущем в поисках динамичных форм хозяйствования имеющийся опыт промышленной демократии (российских и зарубежный) найдет применение на российских предприятиях.

\section{Заключение}

Вопрос, который часто оставался за рамками дискуссии о рабочей демократии, но которого невозможно избежать, по крайней мере, в российской ситуации, мог бы заключаться в одном слове - зачем. Зачем нужны меры по демократизации процессов управления на частных предприятиях, работающих в рыночной среде и ориентированных на достижение максимальной эффективности? Отчасти ответ на этот вопрос дал Тейлор, который полагал, и вполне справедливо, что без вовлечения рядовых работников в процесс управления, без их заинтересованности в конечном результате производство будет развиваться от разумных идей оптимизации в сторону фордизма, предполагающего жесткую регламентацию и рутинизацию труда с высокой степенью технократического принуждения по отношению к рядовым работникам.

Разделение управленческих функций и их предельная концентрация на верхних этажах иерархии принятия решений приводят, в конечном итоге, к появлению водоразделов между управляющими и управляемыми, между классом рабочих и классами управленцев и собственников, которые в российских обстоятельствах часто оказываются одними и теми же лицами. Монополия на власть, которую присваивают себе собственники и управленцы, имеет неизбежным следствием значительный уровень неравенства в распределении не только в рамках предприятия, но и в общественной структуре в целом. Высокие стены между управляющими и управляемыми, между собственниками и рядовыми работниками ведут к деградации населения, накоплению в нем патологических состояний: широкому распространению алкоголизма, наркомании, неуважительному отношению к закону, 
гражданскому и человеческому равнодушию. Речь идет не о досужих экспериментах, диктуемых левыми идеями, а о самих смыслах и способах выживания современного общества, его движении к гуманному состоянию. Именно поэтому вопрос о вовлечении широких масс в управленческие процессы будет раз за разом ставиться не только в развитых обществах, но и обществах, совершающих переход к рынку и только сейчас создающих институты, которые обеспечат его долговременную перспективу.

\section{Литература}

Аристотель (2016) Политика. М.: АСТ.

Ленин В.И. (1970) О кооперации / Полное собрание сочинений. Т. 45. Издание пятое. М.: Политиздат. С. 369-377.

Медушевский А.Н. (2019) Государство-Коммуна: эксперимент рабочей демократии в России 1918 г. и причины его крушения // Мир России. Т. 28. № 2. С. 63-83.

Новиков И.А. (2009) Артель в России во второй половине XIX - начале XX века. К вопросу об определении термина // Вестник Томского Университета. №4(8). С. 147-160.

Рэнд А. (2018) Атлант расправил плечи. Книга 3. М.: Альпина Паблишер.

Смит А. (2016) О природе и причинах богатства народов. М.: ЭКСМО.

Сорокин П. (2005) Социология революции. М.: РОССПЭН.

Clark S. (2007) The Development of Capitalism in Russia, London: Routledge.

Dahrendorf R. (1959) Class and Class Conflict in Industrial Society, Stanford: Stanford University Press.

Dohse K., Jürgens U., Malsch T. (1984) From "Fordism" to "Toyotism"?: The Social Organization of the Labour Process in the Japanese Automobile Industry, Berlin: Wissenschaftszentrum.

Eisenstadt S. (1974) Social Differentiation and Stratification, N.Y.: Scotts, Foresman.

Emery F., Thorsrud E. (1976) Democracy at Work, Leiden: H.E. Stenfert Kroese.

Harrison J.F. (1969) Robert Owen and Owenites in Britain and America, London: Routledge.

Pareto V. (1963) The Mind and Society: a Treatise on General Sociology, N.Y.: Dover Publishers.

Sartwell C. (ed.) (2011) The Practical Anarchist: Writings of Josiah Warren, N.Y.: Fordham University Press.

Slattery M. (2003) Key Ideas in Sociology, Cheltenham: Nelson Thornes LTD.

Sorokin P. (1925) American Millionaires and Multi-millionaires: a Comparative Statistical Study // Social Forces, vol. 3, no 4, pp. 627-640.

Vidal G. (2008) Comment. July 1961 // Esquire, May 19, 2008 // https://www.esquire.com/news-politics/a4595/comment-0761

Webb S., Webb. B. (2013) Industrial Democracy, N.Y.: Read Books.

Wright E.O. (1985) Classes, London: Verso Books. 


\title{
Is Workers' Democracy a Possibility?
}

\author{
M. CHERNYSH*
}

\begin{abstract}
*Mikhail Chernysh - DSc in Sociology, Deputy Director, Institute of Sociology, Russian Academy of Sciences. Address: bld. 5, 24/35, Krzhizhanovskogo St., Moscow, 117218, Russian Federation. E-mail: che@isras.ru
\end{abstract}

Citation: Chernysh M. (2019) Is Workers' Democracy a Possibility? Mir Rossii, vol. 28, no 2, pp. 84-97 (in Russian). DOI: 10.17323/1811-038X-2019-28-2-84-97

\begin{abstract}
Modern social science gave birth to two basic paradigms with different attitudes to worker self-government - one elitist and one democratic. The first is based on Aristotle's idea of the natural character of production hierarchies, an eternal and insurmountable division of society into the government and the governed. The second paradigm calls for the inclusion of workers into the process of management. Each of the paradigms has a long history and its own ideologists. Experiments in the implementation of democratic principles could not tip the balance in favor of either of the two paradigms. Though most of them failed in the short run, ultimately they provided clues for the industrial elites as to how to optimize production, keep workers employed in industries as citizens capable of participating in the political process, on the one side, and becoming consumers, on the other. The success or failure of these experiments was largely determined by the social and political context in which they were held and the ideological orientations of their architects. The early Russian experiments on worker self-government were held in conditions of the total centralization of production, the dominance of the planning system, which reduced the decision-making process on the shop-floor level to an absolute minimum. However, many of the forms of economic self-organization by workers remained in enterprises in the developed world. Cooperatives fully run by the workers themselves demonstrated a high level of economic effectiveness. The inclusion of workers into the management process is a necessary step to solve key problems of contemporary society, such as the problem of inequality.
\end{abstract}

Key words: workers' democracy, industrial democracy, self-government, social experiment, inequality

\section{References}

Aristotle (2016) Politika [Politics], Moscow: AST.

Clark S. (2007) The Development of Capitalism in Russia, London: Routledge. 
Dahrendorf R. (1959) Class and Class Conflict in Industrial Society, Stanford: Stanford University Press.

Dohse K., Jürgens U., Malsch T. (1984) From “Fordism” to “Toyotism”?: The Social Organization of the Labour Process in the Japanese Automobile Industry, Berlin: Wissenschaftszentrum.

Eisenstadt S. (1974) Social Differentiation and Stratification, N.Y.: Scotts, Foresman.

Emery F., Thorsrud E. (1976) Democracy at Work, Leiden: H.E. Stenfert Kroese.

Harrison J.F. (1969) Robert Owen and Owenites in Britain and America, London: Routledge.

Lenin V.I. (1970) O kooperatsii [On Cooperation]. Lenin V.I. Collected Works. Vols. 45. $5^{\text {th }}$ Edition, Moscow: Politizdat, pp. 369-377.

Medushevskiy A.N. (2019) Gosudarstvo-kommuna: eksperiment rabochej demokratii v Rossii 1918 g. i prichiny ego krusheniya [The Communal State: an Experiment in Workers' Democracy in Russia in 1918 and Its Failure]. Mir Rossii, vol. 28, no 2, pp. 63-83.

Novikov I.A. (2009) Artel' v Rossii vo vtoroj polovine XIX-XX stoletiya. Opredelenie termina [Cooperative Units in Russia in the Second Half of the $19^{\text {th }}-$ early $20^{\text {th }}$ Century. The Definition of the Term]. Vestnik Tomskogo Universiteta, no 4(8), pp. 147-160.

Pareto V. (1963) The Mind and Society: a Treatise on General Sociology, N.Y.: Dover Publishers.

Rand A. (2018) Atlant raspravil plechi. Kniga 3 [Atlas Shrugged. Book 3], Moscow: Al'pina Publisher.

Sartwell C. (ed.) (2011) The Practical Anarchist: Writings of Josiah Warren, N.Y.: Fordham University Press.

Slattery M. (2003) Key Ideas in Sociology, Cheltenham: Nelson Thornes LTD.

Smith A. (2016) O prirode i prichinakh bogatstva narodov [Inquiry into the Nature and Causes of the Wealth of Nations], Moscow: EKSMO.

Sorokin P. (1925) American Millionaires and Multi-millionaires: a Comparative Statistical Study. Social Forces, vol. 3, no 4, pp. 627-640.

Sorokin P. (2005) Sotsiologiya revolutsii [The Sociology of Revolution], Moscow: ROSSPEN.

Vidal G. (2008) Comment. July 1961. Esquire, May 19, 2008. Available at: https://www.esquire.com/news-politics/a4595/comment-0761, accessed 31.01.2019.

Webb S., Webb. B. (2013) Industrial Democracy, N.Y.: Read Books.

Wright E.O. (1985) Classes, London: Verso Books. 